\title{
PD-L1 promotes head and neck squamous cell carcinoma cell growth through mTOR signaling
}

\author{
ANYUAN ZHENG $^{1 *}$, FEN LI $^{2 *}$, FUHAI CHEN ${ }^{1}$, JINGJING ZUO $^{1}$, LEI WANG $^{1}$, YONGPING WANG ${ }^{1}$, \\ SHIMING CHEN ${ }^{1,2}$, BOKUI XIAO ${ }^{2}$ and ZEZHANG TAO ${ }^{1,2}$ \\ ${ }^{1}$ Department of Otolaryngology-Head and Neck Surgery, and ${ }^{2}$ Research Institute of Otolaryngology-Head and Neck Surgery, \\ Renmin Hospital of Wuhan University, Wuhan, Hubei 430060, P.R. China
}

Received May 11, 2018; Accepted March 4, 2019

DOI: $10.3892 /$ or.2019.7053

\begin{abstract}
Programmed death-ligand 1 (PD-L1), an immune co-stimulatory molecule, is expressed on various cancer cells and the surface of immune cells. Its overexpression on tumor cells suppresses the immune response to promote tumor cell immune escape. The present study demonstrated that PD-L1 was critical in head and neck squamous cell carcinoma (HNSCC) carcinogenesis. Immunohistochemical analysis of HNSCC tissue microarrays revealed that PD-L1 was overexpressed in tumor tissue, and its expression increased as tumor malignancy progressed (from grade I to IV). Subsequently, the expression of PD-L1 was knocked down or overexpressed in the HNSCC cell lines Cal-27 and Fadu. It was demonstrated that PD-L1 significantly induced HNSCC cell proliferation and colony forming ability. Cell proliferation was also promoted in Cal-27 cell xenograft BALB/c nude mice. In addition, it was determined by western blotting that the PD-L1-mediated increase in HNSCC cell proliferation may have been associated with the activation of mammalian target of rapamycin (mTOR) signaling pathway. Furthermore, mTOR inhibitor (rapamycin) prevented the increase in proliferation. Based on these results, it was concluded that PD-L1 promoted cell proliferation of HNSCC cells through mTOR signaling, and blocking PD-L1 may be conducive in HNSCC therapy.
\end{abstract}

\section{Introduction}

Head and neck squamous cell carcinoma (HNSCC) is the seventh most common cancer type worldwide, with $>500,000$ new cases of HNSCC diagnosed worldwide every year.

Correspondence to: Professor Zezhang Tao, Department of Otolaryngology-Head and Neck Surgery, Renmin Hospital of Wuhan University, 238 Jie-Fang Road, Wuhan, Hubei 430060, P.R. China E-mail: taozezhang@hotmail.com

*Contributed equally

Key words: head and neck squamous cell carcinoma, programmed death-ligand 1, proliferation, mammalian target of rapamycin
Approximately $60 \%$ of HNSCC are diagnosed at an advanced stage, and the prognosis is poor, despite the numerous forms of treatment available $(1,2)$. In recent decades, the 5-year survival rate has improved (3). Although the development of new therapies and advanced examination techniques has prolonged the life of the patients, HNSCC is considered difficult to treat, with the exception of early stage tumors (3). In order to increase patient quality of life, a strategy for the early detection of HNSCC is urgently required. Several biomarkers have been associated with the diagnosis and prognosis of HNSCC, but few have demonstrated adequate clinical efficacy (4).

Programmed death-ligand 1 (PD-L1) is an immune co-stimulatory molecule that belongs to the B7-H gene family (5). It is expressed on many tumor cell types and the surface of immune cells, including B cells, T cells, myeloid dendritic cells and macrophages (6). PD-L1 serves an important role in regulating cellular immunity. PD-L1 combined with programmed cell death protein 1 (PD-1) inhibits the migration and proliferation of $\mathrm{T}$ cells, as well as the secretion of cytotoxic mediators, thus limiting its antitumor effects on tumor cells $(7,8)$. Therefore, anti-PD-L1 monoclonal antibodies ( $\alpha$ PD-L1) are effective in oncotherapy, and antitumor immunity may be enhanced by inhibiting the expression of PD-L1 (9). Anti-PD-L1 monoclonal antibodies have shown considerable promise in the treatment of melanoma, renal cell carcinoma and non-small cell lung cancer (10). The PD-L1/PD-1 axis has gained increasing attention in cancer immunotherapy and immunopathogenesis (11). The majority of research has focused on antitumor immunity, particularly in T cells. However, tumor-intrinsic PD-L1 signals have not been extensively investigated (12). Recently, the regulation of tumor cell proliferation by PD-L1 family members has gained increasing attention; it has been revealed that PD-L1 participates in epithelial-mesenchymal transition (EMT) regulation $(13,14)$, and is closely associate with cell cycle progression $(15,16)$ and the expression of proliferation marker Ki-67 in human breast cancer (16). Based on these previous findings, it was speculated that tumor-intrinsic PD-L1 signaling may have broad biological effects, which require further investigation.

In the present study, the function of PD-L1 in HNSCC was investigated. Immunohistochemical analysis was used to detect PD-L1 expression in HNSCC tissues. Next, it was demonstrated that PD-L1 promoted HNSCC cell proliferation 
in vitro and in vivo. In addition, the potential mechanisms underlying the PD-L1-mediated increase in HNSCC cell proliferation were explored. The current research aimed to provide experimental evidence for the use of $\mathrm{PD}-\mathrm{L} 1$ as a therapeutic target in HNSCC.

\section{Materials and methods}

Patient selection and tissue microarray (TMA). The independent tissue microarrays were purchased (LP803 and LP804; US Biomax, Inc., Rockville, MD, USA). The tissue microarrays consisted of 110 laryngocarcinoma tissues, five normal laryngeal tissues and five samples of normal adjacent laryngeal tissue (NAT), which included 106 men and 14 women. Detailed tissue microarray information is presented in Tables I and II.

Immunohistochemical staining and evaluation. PD-L1 antibody (cat. no. 13684; Cell Signaling Technology, Inc., Danvers, MA, USA) was used for immunohistochemical staining, and the method of immunohistochemical staining was performed as previously described (17). To further analyze the immunohistochemical staining results, all TMAs were scored for frequency (0-4) and intensity (0-3) under an Olympus BX51 microscope (Olympus Corp., Tokyo, Japan). The scores of frequency were assigned when 0-25, 26-50, 51-75 and 76-100\% of the tumor cells stained positive. The scores of intensity (0-3) respectively represented: 0 , negative; 1 , weak; 2 , moderate; and 4 , strong. The composite expression scores (CES) utilized the following formula: CES = intensity $\mathrm{x}$ frequency.

Cell culture and transfection. Two HNSCC cell lines (Cal-27 and $\mathrm{FaDu}$ ) were purchased from Type Culture Collection of the Chinese Academy of Sciences (Shanghai, China). All cells were cultured in Dulbecco's modified Eagle's medium (DMEM; Thermo Fisher Scientific, Inc., Waltham, MA, USA) with $10 \%$ fetal bovine serum (FBS; Gibco; Thermo Fisher Scientific, Inc.), $20 \mathrm{mg} / \mathrm{ml}$ ampicillin and $20 \mathrm{mg} / \mathrm{ml}$ kanamycin at $37^{\circ} \mathrm{C}$ in an incubator with $5 \% \mathrm{CO}_{2}$.

To generate the stable PD-L1-overexpressing (PD-L1 ${ }^{\text {over }}$ ) and PD-L1 knockdown (PD-L1 ${ }^{\mathrm{RNAi}}$; lentivirus transduction particles containing PD-L1 shRNA) cell lines, as well as negative control $(\mathrm{NC})$ groups (PD-L1 ${ }^{\text {ver NC }}$ and $\mathrm{PD}-\mathrm{L1}^{\mathrm{RNA}}$ ${ }^{\mathrm{NC}}$ ), lentivirus transduction particles containing GFP label (cat. nos. GOCL3581014115 and GICL2481014115; Shanghai GeneChem Co., Ltd., Shanghai, China) were transfected (multiplicity of infection=20) into Cal-27 and $\mathrm{FaDu}$ cells $\left(2 \times 10^{5}\right.$ cells/well), and the stable transfected Cal-27 and $\mathrm{FaDu}$ cell lines were selected by culturing for 1 week in complete medium (DMEM with 10\% FBS, ampicillin and kanamycin), which also contained puromycin $(2 \mu \mathrm{g} / \mathrm{ml})$.

Cell proliferation and colony formation assay. Cell proliferation was determined using Cell Counting Kit-8 (CCK-8; Dojindo Molecular Technologies, Inc., Kumamoto, Japan) and EdU incorporation (cat. no. C10310-1; Guangzhou RiboBio Co., Ltd., Shanghai, China) assays, according to the manufacturer's instructions. For the CCK-8 assay, cells were seeded in 96-well plates at $1 \times 10^{3}$ cells/well in DMEM with $10 \%$ FBS, and treated with rapamycin $(10 \mathrm{nM})$ for the total culture period of $72 \mathrm{~h}$. The absorbance was measured at $450 \mathrm{~nm}$ by a microplate
Table I. LP803 tissue microarray patient characteristics.

\begin{tabular}{lc}
\hline Characteristic & Number of patients $(\%)$ \\
\hline Number of patients & $80(100)$ \\
Mean age, years & $57.35 \pm 8.47$ \\
Sex & \\
Female & $9(11.25)$ \\
Male & $71(88.75)$ \\
Localization & \\
Larynx & $80(100)$ \\
Differentiation & \\
1 & $24(33.8)$ \\
2 & $42(59.2)$ \\
3 & $5(7.0)$ \\
\hline
\end{tabular}

Nine cases did not include differentiation information.

Table II. LP804 tissue microarray patient characteristics.

Characteristic Number of patients (\%)

A, Patients with laryngocarcinoma

Number of patients

40 (100)

Mean age, years

$55.25 \pm 13.39$

Sex

Female

$5(12.5)$

Male

$35(87.5)$

Localization

Larynx

$40(100)$

T classification

T1

$3(10.3)$

T2

11 (38)

T3

$3(10.3)$

T4

$12(41.4)$

$\mathrm{N}$ classification

No

$22(73.3)$

$\mathrm{N}+$

8 (26.7)

Differentiation

1

$12(41.4)$

2

$15(51.7)$

2 (6.9)

\section{B, Healthy controls}

Number of patients

$10(100)$

NAT

$5(50)$

Normal laryngeal tissue

$5(50)$

Of the laryngocarcinoma cases, one did not include $\mathrm{T}$ classification; another did not include differentiation information. 

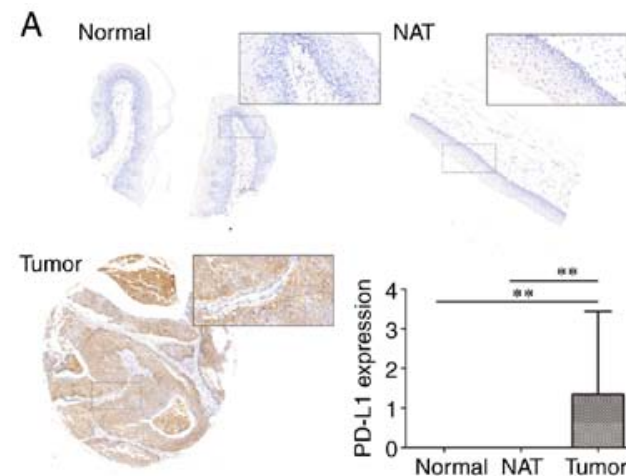

B
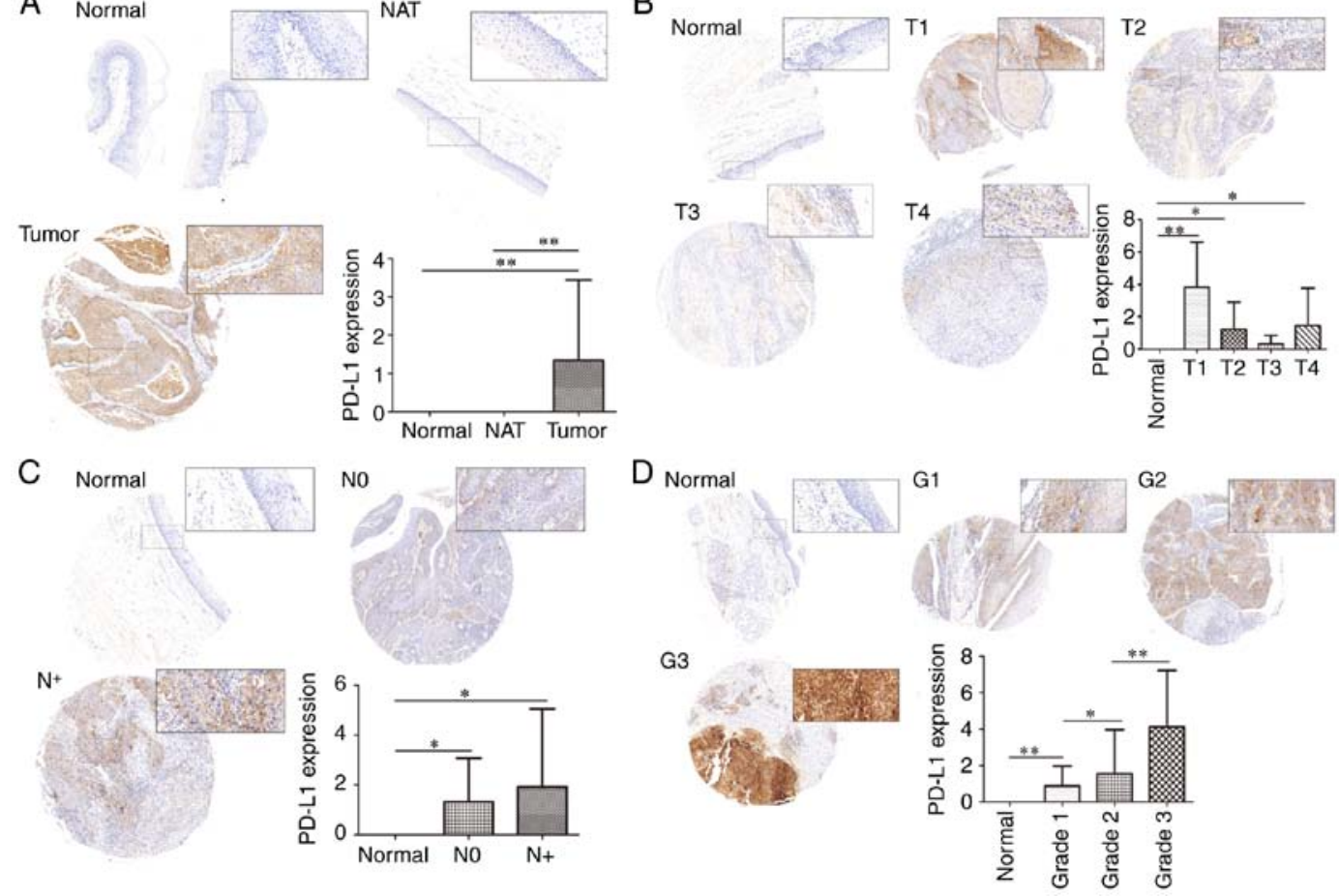

Figure 1. PD-L1 expression in HNSCC. Representative images of immunohistochemical staining for PD-L1 protein expression in (A) normal, NAT and tumor tissue, as well as in (B) different T-stages, (C) N-stages and (D) tumor grades. Magnifications, $\mathrm{x} 40$ and x200. ${ }^{*} \mathrm{P}<0.05$, ${ }^{* *} \mathrm{P}<0.01$. PD-L1, programmed death-ligand 1; HNSCC, head and neck squamous cell carcinoma; NAT, normal adjacent laryngeal tissue.

reader (Perkin Elmer) at 0, 24, 48 and $72 \mathrm{~h}$. For the EdU proliferation assay, tumor cells $\left(5 \times 10^{6}\right.$ cells/well $)$ were plated into 6-well plates in DMEM with 10\% FBS, and directly labeled using the Cell-Light ${ }^{\mathrm{TM}}$ EdU Apollo ${ }^{\circledR} 567$ in vitro Imaging kit, according to the manufacturer's instructions.

For the colony formation assay, cells were seeded into 6-well plates (200 cells/well) and incubated in complete medium for 12 days at $37^{\circ} \mathrm{C}$. The 6 -well plates were washed with PBS and stained with $0.1 \%$ crystal violet at room temperature for 15 min. Colonies which consisted of $>50$ cells were counted under an Olympus IX51 microscope (Olympus Corp.).

Reverse transcription-quantitative polymerase chain reaction $(R T-q P C R)$. Total RNA was isolated with TRIzol ${ }^{\mathrm{TM}}$ reagent (Thermo Fisher Scientific, Inc.). RNA $(1 \mu \mathrm{g})$ was reverse transcribed using the Super RT Reverse Transcriptase reagent kit (Beijing CoWin Biotech Co., Ltd., Beijing, China) according to the manufacturer's instructions. qPCR was conducted in a $25 \mu 1$ reaction system, using the 7500 Fast Real-Time PCR System (Applied Biosystems; Thermo Fisher Scientific, Inc.) and amplified with transcript-specific primers and SYBR $^{\circledR}$-Green Master Mix (Thermo Fisher Scientific, Inc.), according to the manufacturer's instructions. Relative gene expression was calculated using the $2^{-\Delta \Delta \mathrm{Cq}}$ method (18), with GAPDH as the internal control. PD-L1 (cat. no. HQP008443) and GAPDH (cat. no. HQP006940) primers were purchased from GeneCopoeia, Inc. (Rockville, MD, USA). The primer sequences were as follows: PD-L1 forward, 5'-TAGAATTCA TGAGGATATTTGCTGTCTT-3' and reverse, 5'-TAGGAT CCTTACGTCTCCTCCAAATGTG-3'; GAPDH forward, 5'-TGACTTCAACAGCGACACCCA-3' and reverse, 5'-CAC CCTGTTGCTGTAGCCAAA-3.
Xenograft study. Female BALB/c nude mice ( $\mathrm{n}=20 ; 4$ weeks old; 16-18 g) were purchased from Beijing Vital River Laboratory Animal Technology Co., Ltd. (Beijing, China) and underwent adaptive feeding 1 week before the experiment. Mice were housed at constant temperature $\left(20-25^{\circ} \mathrm{C}\right)$ and humidity (40-70\%) in a $12 \mathrm{~h}$ light/dark cycle, with free access to sterile water and standard chow. The nude mice were randomly divided into four groups (PD-L1 ${ }^{\text {over NC}, ~ P D-L 1 ~}{ }^{\text {over }}$, PD-L1 ${ }^{\text {RNAi NC }}$ and PD-L1 ${ }^{\text {RNAi}} ; n=5$ each). Cal-27 cells were selected to establish subcutaneous xenotransplanted tumor model since Cal-27 cells are more superior than FaDu cells in establishing a subcutaneous xenotransplanted tumor model. Cells $\left(2 \times 10^{6}\right)$ were suspended in PBS (200 $\mu$ l cell suspension) and injected into the right side of the mice's backs. Xenograft tumor diameters were measured every week, and tumor volumes were calculated using the following equation: Volume $=1 / 2 \mathrm{x}$ length $\mathrm{x}$ width ${ }^{2}$. The maximum tumor size was $20 \mathrm{~mm}$. Nude mice were sacrificed and tumors surgically removed 12 weeks after inoculation.

Western blotting. Cal-27 and FaDu cells were harvested and lysed in radioimmunoprecipitation assay lysis buffer (Thermo Fisher Scientific, Inc.) supplemented with protease and phosphatase inhibitors (Roche Applied Science, Penzberg, Germany). Protein concentration was determined by the bicinchoninic acid protein assay. Lysates $(20 \mu \mathrm{g}$ of protein loaded per lane) were resolved by $10 \%$ SDS-PAGE, transferred to polyvinylidene difluoride membranes and immunoblotted with specific primary antibodies (all 1:800) overnight at $4^{\circ} \mathrm{C}$ against PD-L1 (cat. no. 9234T; Cell Signaling Technology, Inc.), protein kinase B (Akt; cat. no. 4691T; Cell Signaling Technology, Inc.), phosphorylated (p)-Akt ${ }^{\mathrm{S} 473}$ 
A

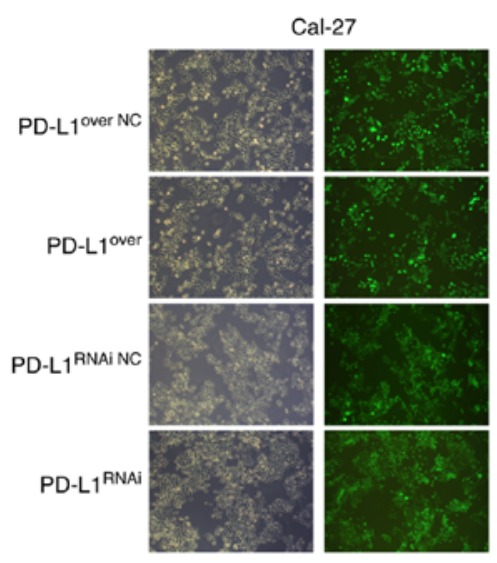

B

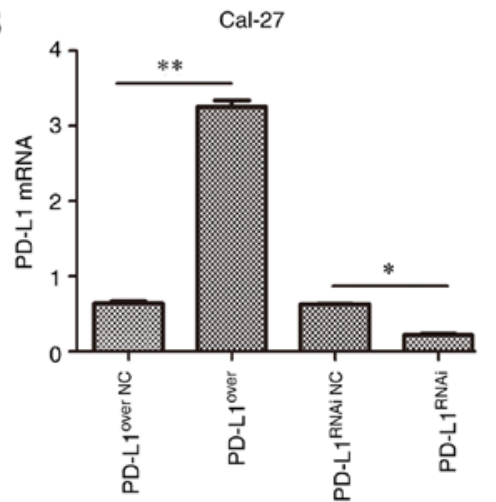

C
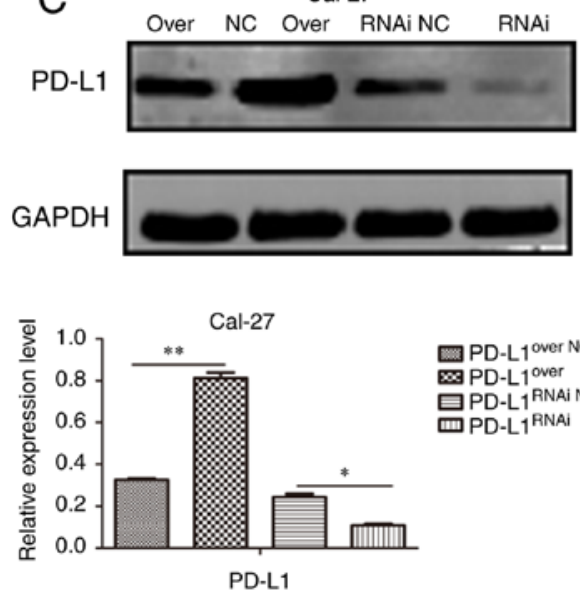

$\mathrm{FaDu}$
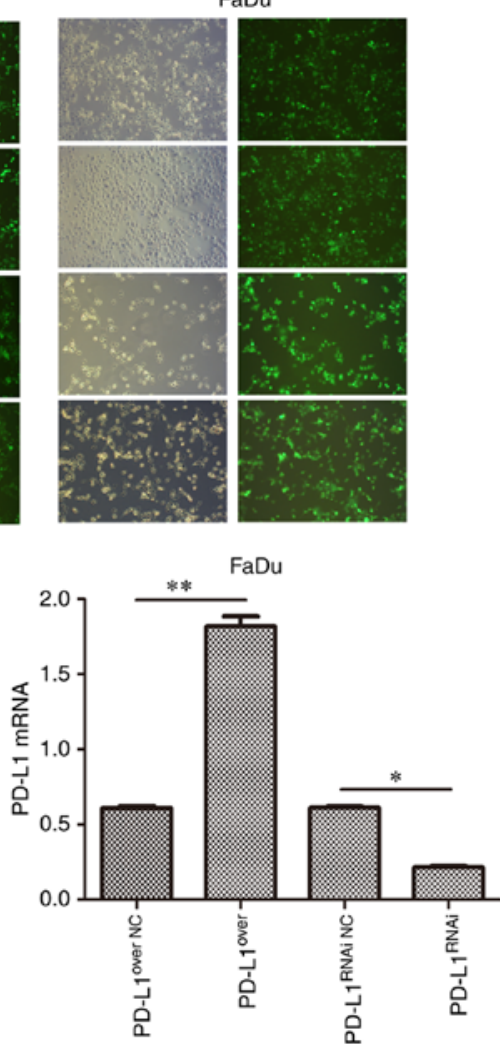

$\mathrm{FaDu}$
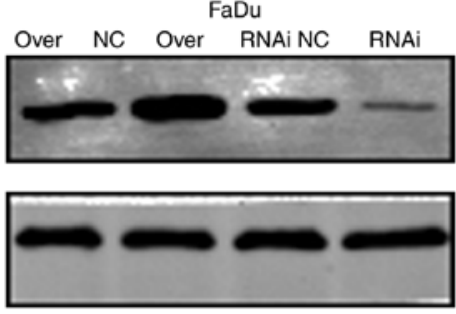

$\mathrm{FaDu}$

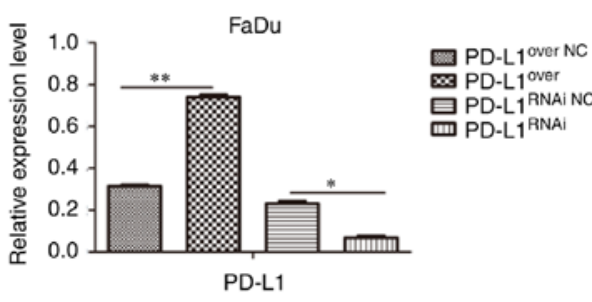

Figure 2. Lentivirus transduction particles were transfected into Cal-27 and FaDu cells. (A) Representative green fluorescent images of transfected cells. (B) Relative expression of PD-L1 mRNA was detected by quantitative polymerase chain reaction. Data were expressed as the mean \pm standard deviation. (C) Western blot analysis of PD-L1 protein expression in PD-L1 ${ }^{\text {over }}, \mathrm{PD}-\mathrm{L} 1^{\mathrm{RNAi}}, \mathrm{PD}-\mathrm{L} 1^{\text {over NC }}$ and $\mathrm{PD}-\mathrm{L} 1^{\mathrm{RNAi}}{ }^{\mathrm{NC}}$ expression. ${ }^{*} \mathrm{P}<0.05$ and ${ }^{* *} \mathrm{P}<0.01 . \mathrm{PD}-\mathrm{L} 1$, programmed death-ligand 1; PD-L1 ${ }^{\text {over }}$, PD-L1-overexpressing; PD-L1 ${ }^{\text {RNAi }}$, PD-L1 knockdown; NC, negative control.

(cat. no. 4060T; Cell Signaling Technology, Inc.), 70 kDa ribosomal protein S6 kinase 1 (P70S6K; cat. no. 2708S; Cell Signaling Technology, Inc.), p-P70S6K ${ }^{\mathrm{T} 389}$ (cat. no. 9234T; Cell Signaling Technology, Inc.) and GAPDH (cat. no. 5174S; Cell Signaling Technology, Inc.). Following immunoblotting with IRDye ${ }^{\circledR}$ goat-anti rabbit IgG flourescence secondary antibodies (dilution 1:20,000; cat. no. 926-32211; LI-COR Biosciences, Lincoln, NE, USA) at room temperature for $1 \mathrm{~h}$, the membranes were scanned by an Odyssey infrared imaging system (LI-COR Biosciences).

Statistical analysis. All values are expressed as the mean \pm standard deviation of three independent experimental repeats.
Statistical analyses were performed in SPSS 19.0 (SPSS, Inc., Chicago, IL, USA), using one-way analysis of variance with Tukey's post hoc test. $\mathrm{P}<0.05$ was considered to indicate a statistically significant difference.

\section{Results}

PD-L1 expression in HNSCC. In order to examine the expression of PD-L1 in HNSCC, NAT and normal tissues, TMAs of HNSCCs stained for PD-L1 were analyzed, and the CES of every clinical sample was measured. PD-L1 expression was compared and associated with clinical characteristics, including tumor grade and TNM staging. 

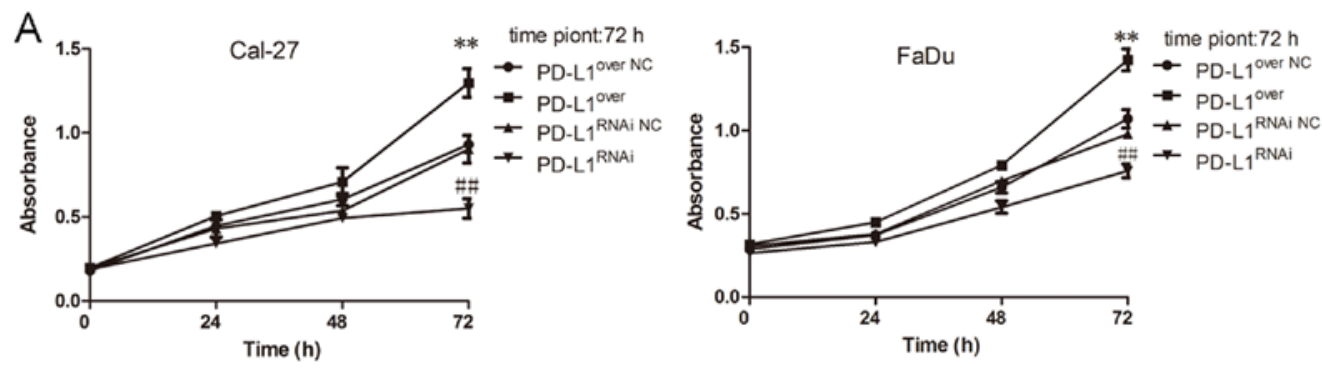

B

Cal-27

FaDu
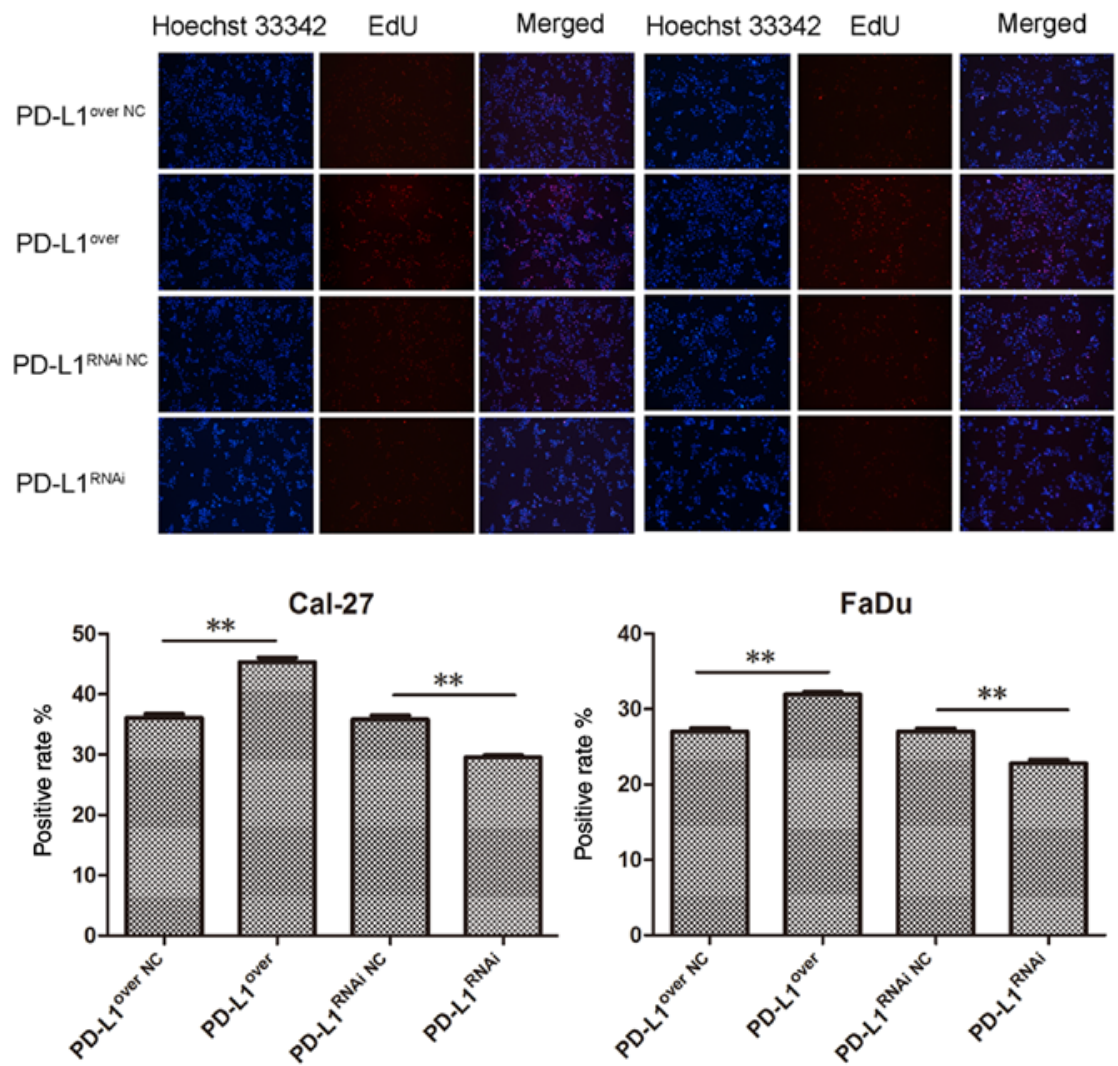

Figure 3. PD-L1 overexpression promotes the proliferation of HNSCC cell lines. (A) HNSCC cell proliferation was detected with Cell Counting Kit-8 assays, ${ }^{* *} \mathrm{P}<0.01$ vs. PD-L1 ${ }^{\text {over NC }},{ }^{\# \#} \mathrm{P}<0.01$ vs. PD-L1 ${ }^{\mathrm{RNAi}}{ }^{\mathrm{NC}}$. (B) HNSCC cells were labeled with Cell-Light ${ }^{\mathrm{TM}}$ EdU (red), and nuclei were stained by Hoechst 33342 (blue). Histograms represent the positive rate of EdU staining.

PD-L1 expression in tumor tissue was significantly higher than in normal tissue and NAT $(\mathrm{P}<0.01)$, with no significant difference in PD-L1 expression between normal tissue and NAT ( $>>0.05$; Fig. 1A). T-stage analysis revealed that although the expression of PD-L1 in normal tissue was significantly higher in $\mathrm{T} 1(\mathrm{P}<0.01), \mathrm{T} 2(\mathrm{P}<0.05)$ and T4 $(\mathrm{P}<0.05)$, there was no statistical significance in PD-L1 expression in T3 $(\mathrm{P}>0.05$; Fig. 1B). It is likely that a larger number of samples are required to fully investigate the relationship between T-stage and PD-L1, as the sample sizes of $\mathrm{T} 1$ and $\mathrm{T} 3$ were insufficient, and the expected increase in PD-L1 expression with T stage progression was not observed. For the N-stage, representative images were presented in Fig. 1C. The CES of the PD-L1 protein expression revealed that there was no significant differences between the $\mathrm{N}$-stages $(\mathrm{P}>0.05)$. As $\mathrm{N}$-stage indicates regional lymph node metastasis, these results suggest that PD-L1 may have no relationship with the regional metastasis of HNSCC. Finally, the expression of PD-L1 among different tumor grades was compared respectively, demonstrating that an increased tumor grade was associated with increased PD-L1 expression (Fig. 1D).

$P D-L 1$ regulates the proliferation and colony formation in HNSCC cell lines in vitro. To explore the function of PD-L1, stable PD-L1-overexpressing (PD-L1 ${ }^{\text {over }}$ ), PD-L1 knock-

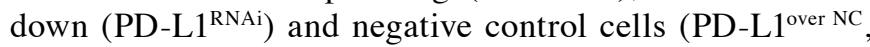
PD-L1 $\left.{ }^{\text {RNAi NC}}\right)$ were generated, and the expression of PD-L1 was detected by RT-qPCR and western blotting. The stably transfected Cal-27 and FaDu cells were established and representative micrographs showed the immunofluorescence of GFP in cells (Fig. 2A). It was demonstrated that the lentiviral transduction particles successfully altered PD-L1 protein (Fig. 2B) and gene (Fig. 2C) expression. PD-L1 ${ }^{\text {RNAi }}$ HNSCC cell proliferation was significantly reduced, compared with its respective control group, with the PD-L1 ${ }^{\text {over }}$ cells exhibiting the highest rate of proliferation (Fig. 3A). 

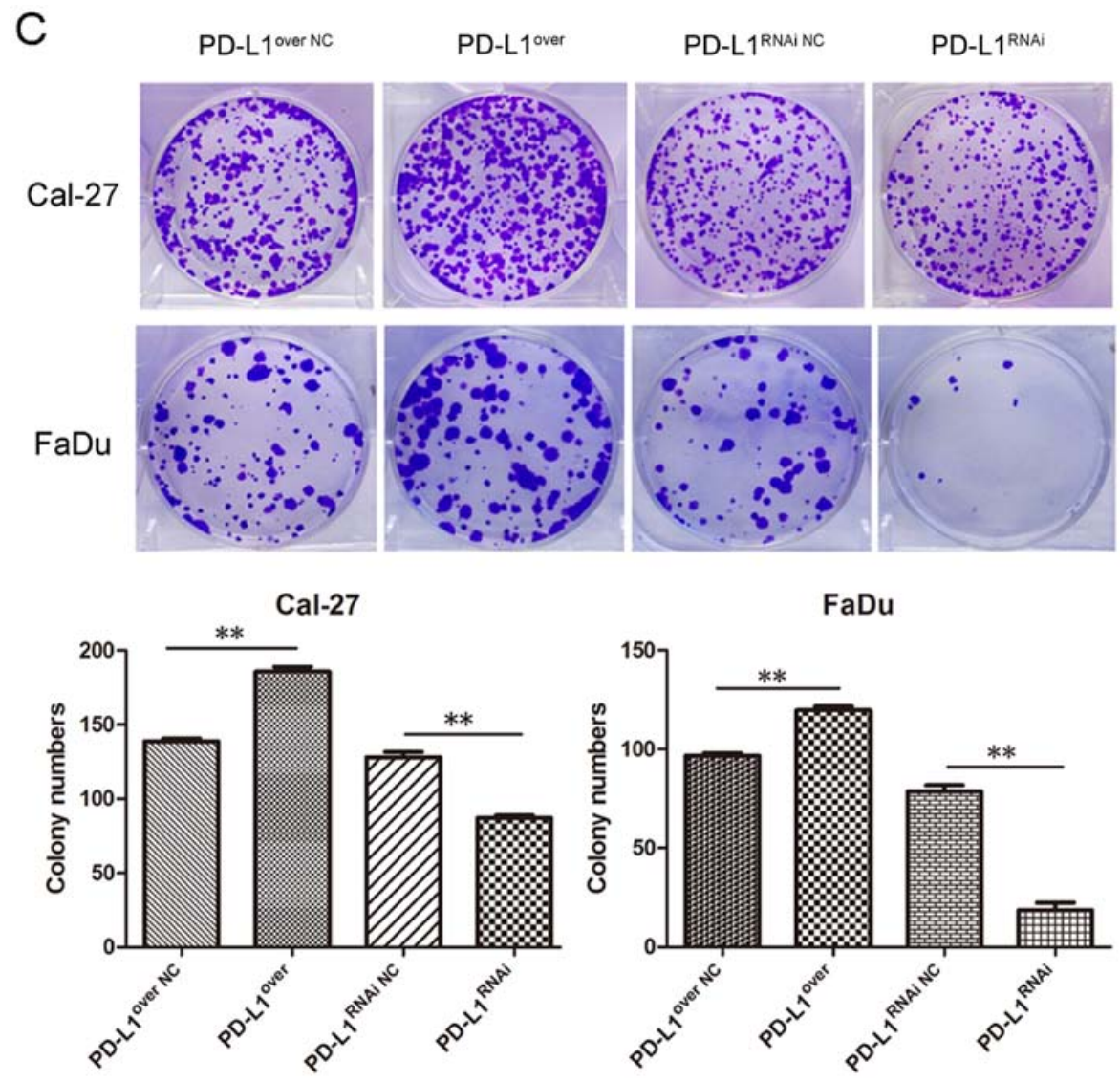

Figure 3. Continued. PD-L1 overexpression promotes the proliferation of HNSCC cell lines. (C) Colony formation assay. Cell colony numbers (>50 cells/unit) were counted. Data were expressed as the mean \pm standard deviation. ${ }^{* *} \mathrm{P}<0.01$. PD-L1, programmed death-ligand 1; HNSCC, head and neck squamous cell carcinoma; PD-L1 ${ }^{\text {ver }}$, PD-L1-overexpressing; PD-L1 ${ }^{\mathrm{RNAi}}$, PD-L1 knockdown; NC, negative control.

Furthermore, the EdU proliferation assay revealed a similar trend, in which the PD-L1-overexpressing cells exhibited the highest red fluorescence (Fig. 3B). Furthermore, the colony forming ability of PD-L1-overexpressing cells was remarkably increased compared with the PD-L1 ${ }^{\text {over NC }}$ group, and colony numbers in the PD-L1 knockdown group were significantly reduced, compared with the PD-L1 ${ }^{\text {RNAi NC }}$ group (Fig. 3C).

PD-L1 upregulates mTOR signaling in HNSCC cell lines. To investigate the potential mechanism by which PD-L1 promoted cell growth in HNSCC cells, the expression levels of proteins associated with mTOR signaling and cell proliferation were detected by western blotting (Fig. 4A). Compared with their corresponding control groups, $\mathrm{p}-\mathrm{P} 70 \mathrm{~S} 6 \mathrm{~K}^{\mathrm{T} 389}$ and $\mathrm{p}-\mathrm{Akt}^{\mathrm{S} 473}$ expression was significantly increased on the $\mathrm{PD}-\mathrm{Ll}^{\text {over }}$ group, but significantly decreased in the PD-L1 ${ }^{\mathrm{RNAi}}$ group (Fig. $4 \mathrm{~B}$ ).

Effect of PD-L1 expression on tumor growth in vivo. To validate whether the expression of PD-L1 affected tumor growth in vivo, Cal-27 cells were used to establish a xenograft mouse model. At the 12 week end point, the tumor growth curve (Fig. 5A) showed that the tumor volume in the Cal-27-PD-L1 ${ }^{\text {over }}$ group was significantly larger than the control group $(\mathrm{P}<0.01)$, and the tumor volume in the $\mathrm{PD}-\mathrm{L1}^{\mathrm{RNAi}}$ group was the smallest $(\mathrm{P}<0.05)$. The tumors were removed and measured on week 12 (Fig. 5B), and the average volume was calculated (Fig. 5C). These results demonstrated that PD-L1 accelerated tumor growth, suggesting an important role for PD-L1 in regulating the tumor cell growth in vivo. No significant differences in animal weight were detected (Fig. 5D).

PD-L1 enhances the sensitivity of HNSCC cells to mTOR inhibitor in vitro. As PD-L1 upregulated the expression of proteins involved in mTOR signaling, the effects of mTOR inhibitor rapamycin were investigated. Cellular proliferation was significantly inhibited in the PD-L1 ${ }^{\text {over }}$ group following treatment with mTOR inhibitor. PD-L1 ${ }^{\text {over }} \mathrm{Cal}-27$ cells were the most sensitive to rapamycin in the four groups, and the PD-L1 ${ }^{\mathrm{RNAi}}$ tumor cells were the most tolerant to rapamycin-mediated proliferation inhibition (Fig. 6A-C). The result obtained in Cal-27 and FaDu cells were consistent. Although there was no significant statistical difference between PD-L1 ${ }^{\mathrm{RNAi}}$ and PD-L1 ${ }^{\mathrm{RNAi} \mathrm{NC}}$ groups in FaDu cells, it was still indicated that PD-L1 exerted some regulatory action on tumor cell proliferation, and mTOR inhibitor was effective in preventing the PD-L1-driven proliferative effects. As presented in Fig. 4, PD-L1 knockdown reduced the activation of mTORC1 and mTORC2. In response to rapamycin treatment, p-P70S6K ${ }^{\mathrm{T} 389}$ expression was markedly suppressed, and p-P70S6KT ${ }^{389}$ could mediate a negative feedback loop on phosphoinositide 3-kinase (PI3K)/Akt which was de-repressed by rapamycin, and elevated the level of p-Akt ${ }^{\mathrm{S} 733}$ (Fig. 7A and B). The proportion of p-P70S6 $\mathrm{K}^{\mathrm{T} 389}$ appeared the most markedly decreased in PD-L1 ${ }^{\text {over+RP }}$ cells, compared with PD-L1 ${ }^{\text {over }}$ cells; 
A

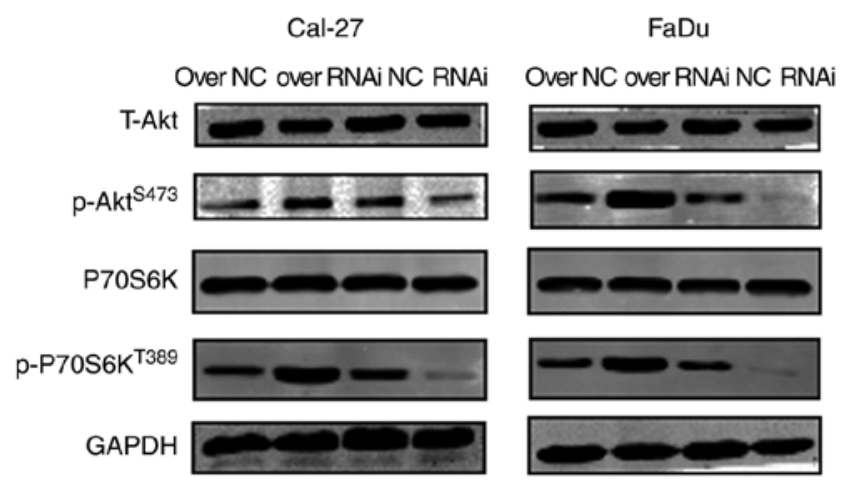

$\mathrm{B}$

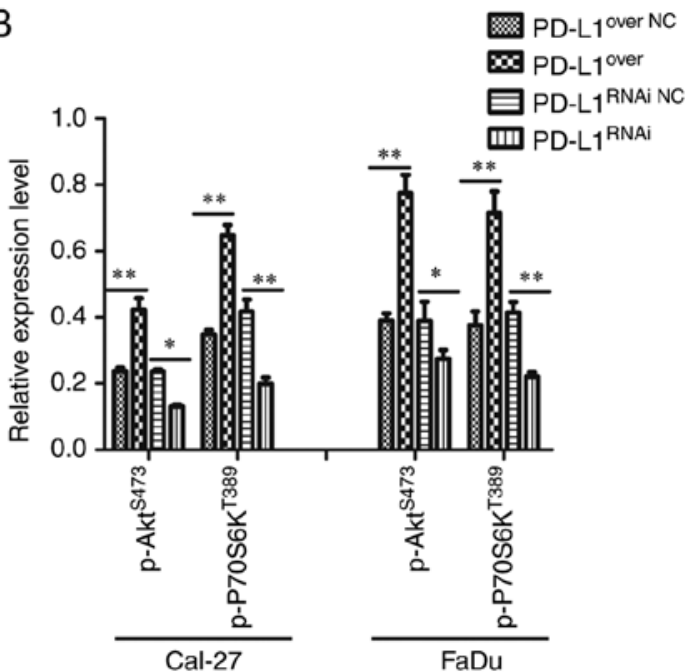

Figure 4. PD-L1 upregulates mTOR signaling in HNSCC cell lines. (A) Western blot analysis of T-Akt, P70S6K, p-P70S6K ${ }^{\mathrm{T} 389}$, p-Akt ${ }^{\mathrm{S} 473}$ and GAPDH expression in PD-L1 ${ }^{\text {over }}$, PD-L1 ${ }^{\mathrm{RNAi}}$ and respective NC cells. (B) p-P70S6K ${ }^{\mathrm{T} 389}$ and $\mathrm{p}-\mathrm{Akt}^{\mathrm{S} 473}$ expression in each group was quantified. ${ }^{*} \mathrm{P}<0.05$ and ${ }^{* *} \mathrm{P}<0.01$. PD-L1, programmed death-ligand 1; T-, total; P70S6K, 70 kDa ribosomal protein S6 kinase 1; p-, phosphorylated; Akt, protein kinase B; PD-L1 ${ }^{\text {over }}$, PD-L1-overexpressing; PD-L1 ${ }^{\mathrm{RNAi}}$, PD-L1 knockdown; NC, negative control.

A

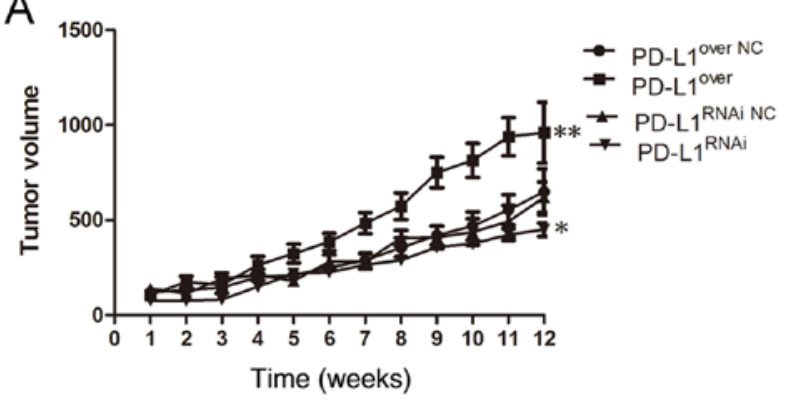

B

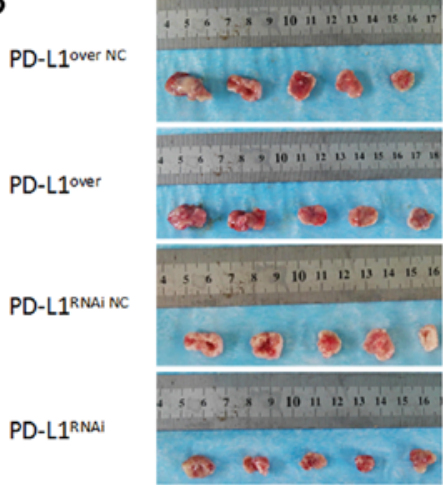

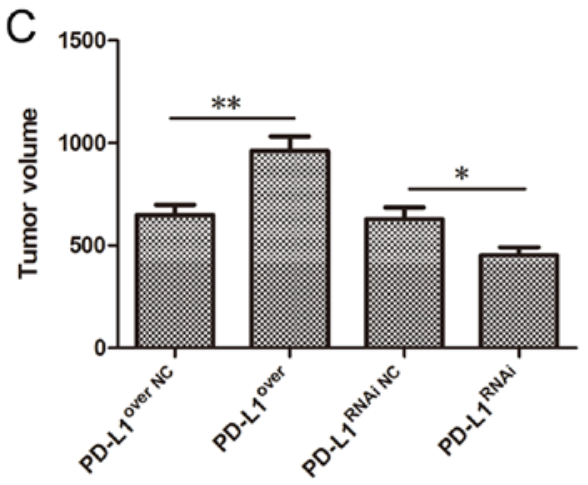

D

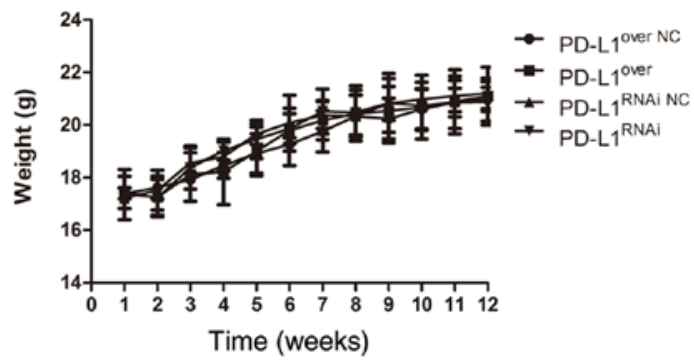

Figure 5. Effects of PD-L1 expression on tumor growth in vivo. (A) PD-L1 expression and tumor growth in the subcutaneous xenotransplanted tumor models. (B) Tumors were removed from nude mice and (C) the average tumor volume was presented in the histogram. (D) The average weight of nude mice was presented. ${ }^{* *} \mathrm{P}<0.01$ and ${ }^{*} \mathrm{P}<0.05$. PD-L1, programmed death-ligand 1; PD-L1 ${ }^{\text {over }}$, PD-L1-overexpressing; PD-L1 ${ }^{\mathrm{RNAi}}$, PD-L1 knockdown; NC, negative control.

and $\mathrm{p}-\mathrm{Akt}^{\mathrm{S} 473}$ of PD-L1 ${ }^{\mathrm{RNAi}}$, which increased, was more than PD-L1 ${ }^{\text {RNAi+RP }}$ (Fig. 7B), further indicating that PD-L1 may have promoted cell growth through mTOR signaling upregulation.

\section{Discussion}

PD-1 is predominantly expressed in activated T/B cells, where its function is to suppress immune cell activation via a physiological self-stabilization mechanism (19). Overactivation of
T/B cells lead to autoimmune diseases, and thus PD-1 has a protective role $(19,20)$. In the tumor microenvironment, infiltrating T cells overexpress PD-1, and PD-L1 and PD-L2 are highly expressed by tumor cells; the ligation of PD-1/PD-L1 inhibits $\mathrm{T}$ cell activation (21). T cell migration and proliferation is inhibited, as well as the secretion of perforin and granzymes by cytotoxic $\mathrm{T}$ cells, which greatly limits their killing effects on tumor cells (22). Blocking the binding of PD-1 to PD-L1 would likely prevent immune escape, 

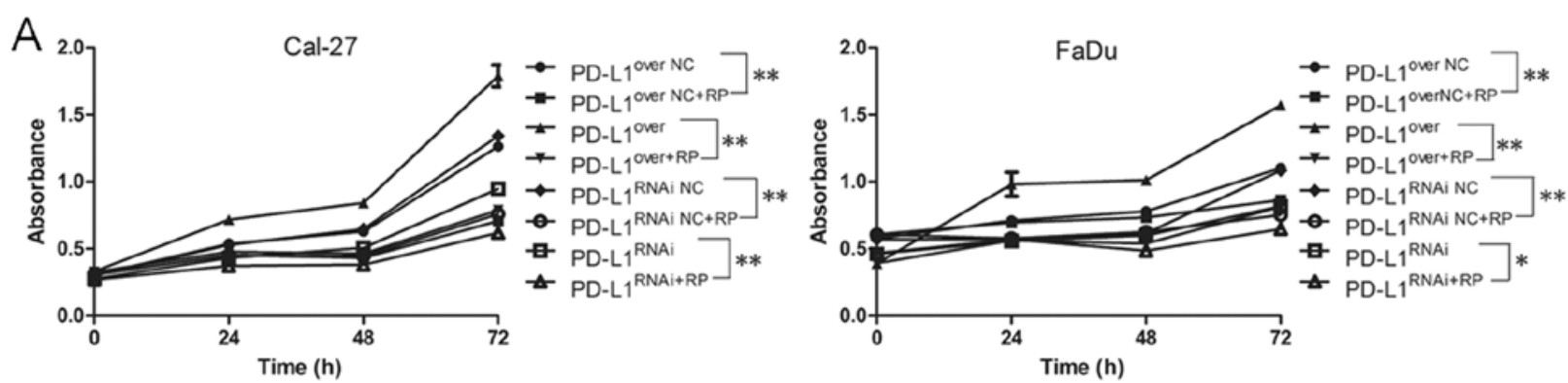

B
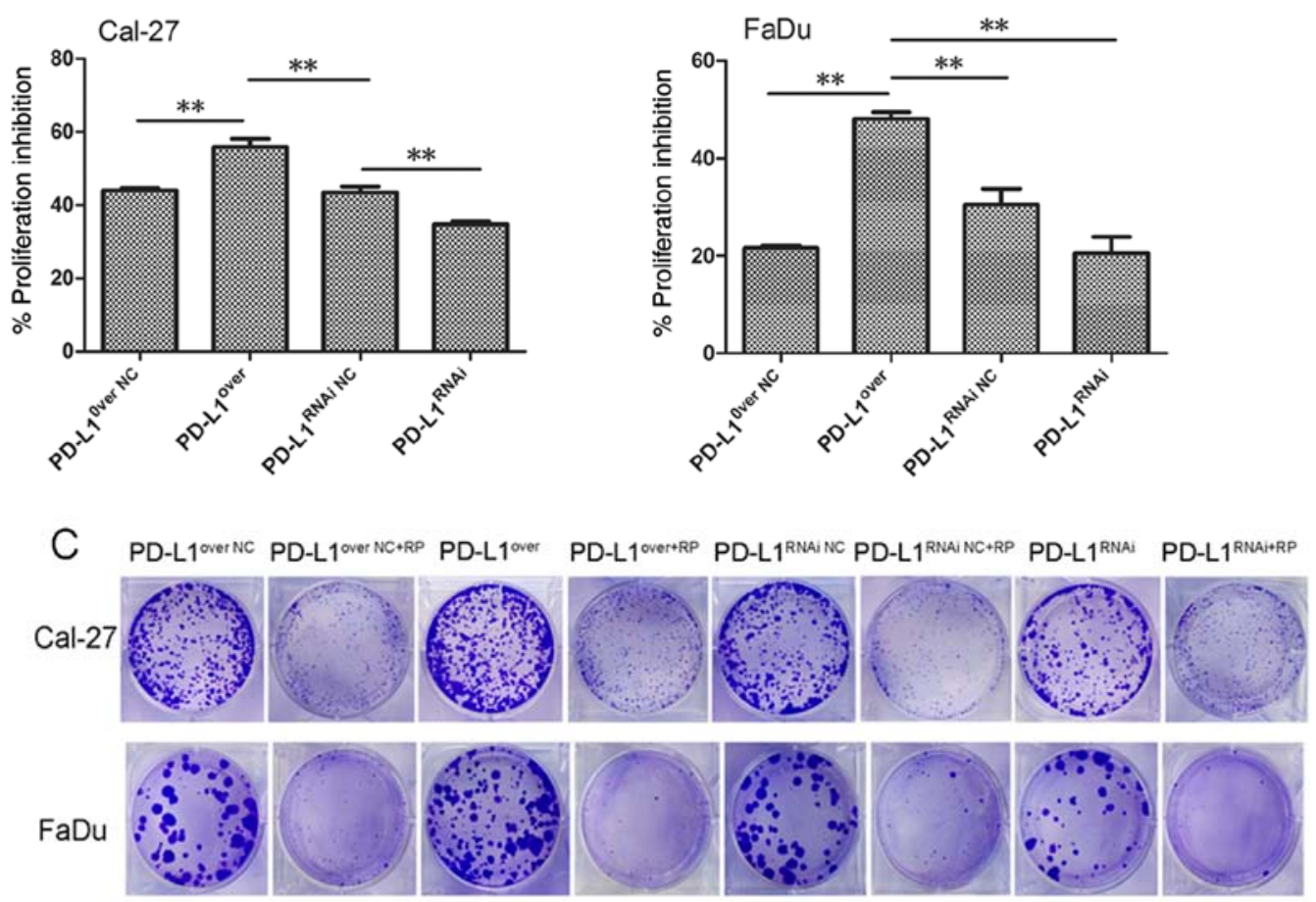

Cal-27+RP
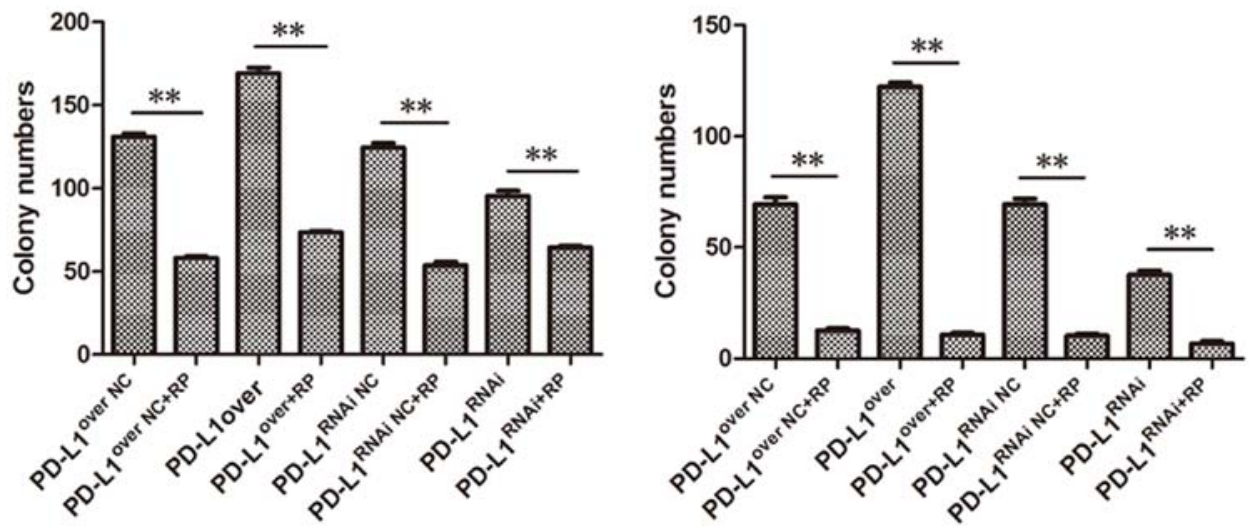

Figure 6. PD-L1 enhances the sensitivity of HNSCC cells to mTOR inhibitor in vitro. (A) HNSCC cells were cultured with rapamycin and cell proliferation was detected by Cell Counting Kit-8 assay (B) and the proliferation inhibition rate was calculated. (C) Colony formation assay results. Cell colony numbers ( $>50$ cells/unit) were counted ${ }^{*} \mathrm{P}<0.05$ and ${ }^{* *} \mathrm{P}<0.01$. PD-L1, programmed death-ligand 1; HNSCC, head and neck squamous cell carcinoma; mTOR, mammalian target of rapamycin; RP, rapamycin; PD-L1 ${ }^{\text {over }}$, PD-L1-overexpressing; PD-L1 ${ }^{\mathrm{RNAi}}$, PD-L1 knockdown; NC, negative control.

enhance antitumor immunity and inhibit tumor progression. At present, the efficacy of PD-1-targeted therapy is very low as a monotherapy, with an overall response rate of $20-50 \%$ in cases with multiple tumors $(23,24)$. However, it has been suggested that combining PD-1-targeted therapy with other therapeutic methods may significantly augment the curative effect and the overall response rate (25). Therefore, the combination of PD-1/PD-L1 inhibition with other therapies requires further research.

As a novel target of immunotherapy, tumor-expressed PD-L1 mediates cancer immunopathogenesis by negatively regulating $\mathrm{T}$ cells (26). However, increasing evidence has 

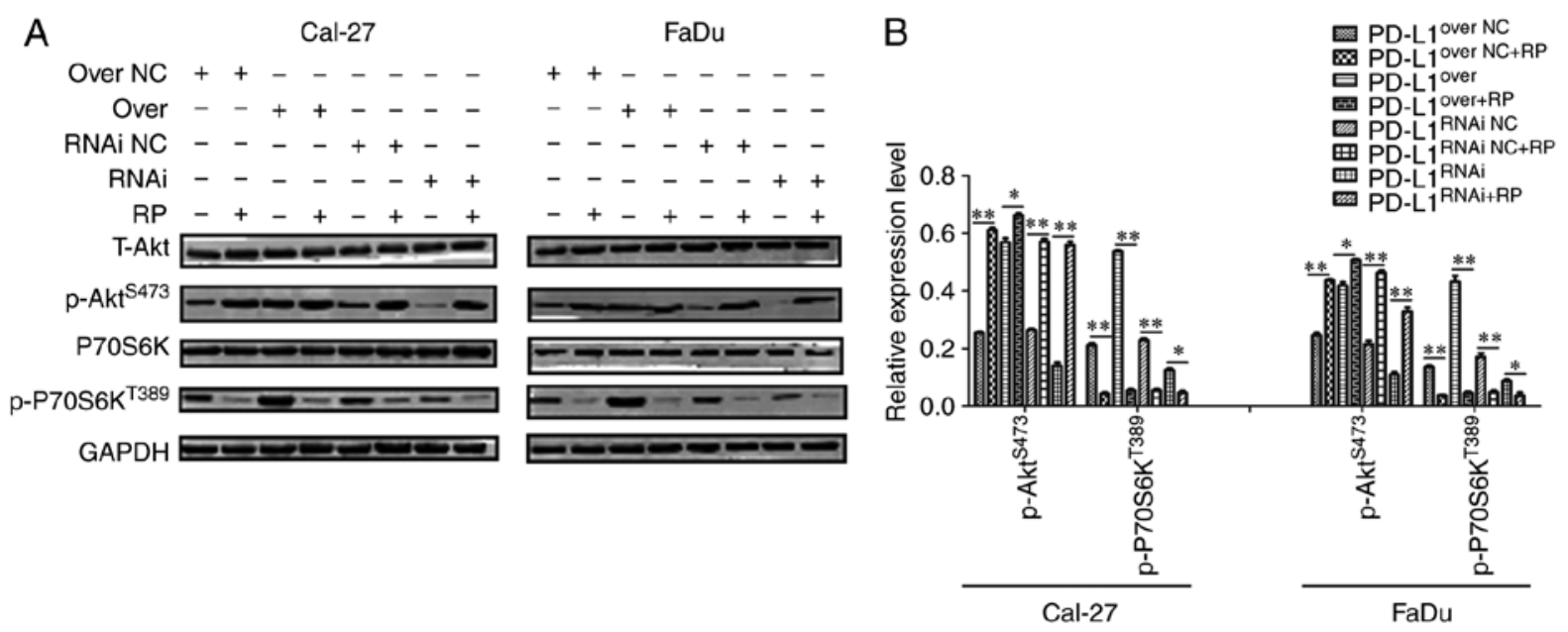

Figure 7. Rapamycin prevents the PD-L1-mediated effects on mTOR expression. (A) Western blot analysis of T-Akt, P70S6K, p-P70S6K ${ }^{\mathrm{T} 389}$, p-Akt ${ }^{\mathrm{S} 73}$ and GAPDH expression in PD-L1 ${ }^{\text {over }}$, PD-L1 ${ }^{\mathrm{RNAi}}$ and respective NC cells with or without rapamycin. (B) p-P70S6K $\mathrm{K}^{\mathrm{T} 389}$ and $\mathrm{p}-\mathrm{Akt} \mathrm{t}^{\mathrm{S} 473}$ expression in each group was quantified. ${ }^{*} \mathrm{P}<0.05$ and ${ }^{* *} \mathrm{P}<0.01$. PD-L1, programmed death-ligand 1; T-, total; $\mathrm{P} 70 \mathrm{~S} 6 \mathrm{~K}, 70 \mathrm{kDa}$ ribosomal protein S6 kinase 1; p-, phosphorylated; Akt, protein kinase B; PD-L1 ${ }^{\text {over }}$, PD-L1-overexpressing; PD-L1 ${ }^{\mathrm{RNAi}}$, PD-L1 knockdown; NC, negative control; mTOR, mammalian target of rapamycin; RP, rapamycin.

suggested that PD-L1 has critical functions in promoting tumor formation and development, without relying on the immune checkpoint $(15,27)$. Previous studies have confirmed PD-L1 mRNA is upregulated in a wide variety of tumors, such as pulmonary adenocarcinoma, breast cancer and squamous lung cancer $(13,28,29)$. A previous study reported that $\mathrm{PD}-\mathrm{L} 1$ protein expression was increased in squamous cell carcinoma (SCC) of the head and neck, esophagus and lung (30). In addition, PD-1 expression is upregulated in response to proinflammatory cytokines IFN- $\gamma$, TNF- $\alpha$ and IL-1 $\beta$, and PD-L1 blockade by a monoclonal antibody efficiently augments the effects of adaptive $\mathrm{T}$ cell immunotherapy in a murine model of PD-L1-transfected SCC, and inhibits the growth of de novo induced PD-L1 ${ }^{+}$SCC $(21,30)$. In the present study, TMAs were obtained to detect PD-L1 expression characteristics in HNSCC. PD-L1 expression was significantly higher in tumor tissue, compared with NAT and normal tissue. Of note, the expression of PD-L1 progressively increased along with the increase of the tumor grades. These results suggested that PD-L1 was associated with HNSCC tumorigenesis. Consistent with the results of the present study, Strome et al (31) also reported that PD-L1 protein was upregulated in SCC and highly expressed in 66\% (16 of 24) of freshly isolated SCC samples of the head and neck (31). However, the relationship between PD-L1 expression and tumor TNM staging remains unclear in certain reports, as well as its relationship with regional lymph node metastasis $(32,33)$. In the present study, the results revealed that PD-L1 expression was not significantly different between $\mathrm{T} / \mathrm{N}$ stages. PD-L1/PD-1 plays an important role in directly regulating the tumor microenvironment, and considering the complicated effects of PD-L1/PD-1 in the tumor and tumor microenvironment (9), it is difficult to illuminate the relationship between PD-L1 and T/N stages. Additionally, the small sample size may have had an impact on the results. Hence, further investigation with a larger number of samples is required.

In addition, the role of PD-L1 as a non-immune checkpoint was demonstrated, which may be a potential therapeutic target in HNSCC. The majority of studies focusing on PD-L1 have predominantly focused on immunity, particularly in T cells $(11,24,31)$. Although it has been reported that blocking PD-L1 affects tumor cell proliferation $(12,27,34)$, it was uncertain whether PD-L1 inhibition suppresses tumor growth in HNSCC. Through the generation of stable PD-L1-overexp ressing (PD-L1 $\left.{ }^{\text {over }}\right)$, and PD-L1 knockdown (PD-L1 ${ }^{\text {RNAi }}$ cell lines, the present study demonstrated that PD-L1 promoted tumor growth in vitro and in vivo. In addition, compared with the control group, PD-L1 ${ }^{\mathrm{RNAi}}$ HNSCC cell proliferation decreased, even in the rapamycin-treated RNAi group. Francisco et al (35) reported that PD-L1 mediates the development of regulatory $\mathrm{T}$ cells via downregulation of the mTOR pathway, coupled with the upregulation of phosphatase and tensin homolog (PTEN). In addition, it has been reported that blocking PD-L1 suppresses mTOR activity $(27,34)$. Our preliminary experiments confirmed that PD-L1 had no significant effects on the expression of key proteins involved in multiple signaling pathways, such as signal transducer and activator of transcription, mitogen-activated protein kinase and nuclear factor- $\kappa \mathrm{B}$. Hence, it was concluded that PD-L1 may have exerted bi-directional effects in regulating the mTOR pathway, although the exact mechanism remains unclear in HNSCC.

The PI3K/Akt/mTOR signaling pathway has critical functions in both solid tumors and hematological malignancies (36). mTOR regulates cell growth, motility, and metabolism; this signaling cascade is frequently upregulated in cancer due to loss of the tumor suppressor PTEN (37). Glycogen synthase kinase-3 (GSK-3) also interacts with and affects the function of downstream components of the PI3K/Akt/mTOR signaling network (38). Bertacchini et al (39) reported that dual inhibition of PI3K/mTOR signaling resensitizes resistant cancer cells to chemotherapy (39). mTOR contains two complexes, mTORC1 and mTORC2. p-P70S6K ${ }^{\mathrm{T} 389}$ is the downstream effector of mTORC1, and p- $\mathrm{Akt}^{\mathrm{s} 473}$ is the downstream effector of mTORC2. mTORC1 and mTORC2 exert important influences on the growth and survival of tumor cells $(40,41)$. In the present study, it was demonstrated that PD-L1 increased 
p-P70S6K $\mathrm{K}^{\mathrm{T} 389}$ and $\mathrm{p}-\mathrm{Akt}^{\mathrm{S} 473}$ expression in HNSCC cell lines, and cells overexpressing PD-L1 proliferated faster than control cells. Thus, PD-L1 may have been capable of regulating both mTORC1 and mTORC2 expression. In addition, mTORC1 inhibitor suppressed p-P70S6K ${ }^{\text {T389 }}$ expression and prevented the PD-L1-mediated increase in proliferation. Cell proliferation inhibition rate of the PD-L1 ${ }^{\text {over }}$ cells was the highest in the four groups following treatment with mTOR inhibitor, and PD-L1 $1^{\mathrm{RNAi}}$ cells were the most resistance to rapamycin-mediated proliferation inhibition. In addition, $\mathrm{p}-\mathrm{Akt}^{\mathrm{S} 473}$ expression was increased in the of PD-L1 $1^{\text {over+RP }}$ cells, compared with the PD-L1 ${ }^{\mathrm{RNAi+RP}}$ cells, this may be the combined effect of p-P70S6K $\mathrm{K}^{\mathrm{T} 389}$-mediated negative feedback loop on phosphoinositide 3-kinase (PI3K)/Akt which was de-repressed by rapamycin and low PD-L1-mediated restraint of $\mathrm{p}-\mathrm{Akt}^{\mathrm{S} 473}$. Therefore, further study is required to understand the mutual influence of both these factors.

Accumulating evidence has revealed that the curative effect of anti-PD-L1 treatment is superior to anti-cytotoxic T-lymphocyte protein 4 therapy $(42,43)$. It has been speculated that anti-PD-L1 may not only prevent PD-L1-mediated immune escape, but may also restrain PD-L1-mediated carcinogenesis. This may also be the reason why anti-PD-L1 therapy has been reported to be more effective than immunotherapy in tumors (42). In addition, it suggests that tumor intrinsic PD-L1 signals have an antitumor effect.

In conclusion, the present study revealed that the expression of PD-L1 was significantly higher in HNSCC compared with normal tissues or cell lines, and the expression of PD-L1 increased as the tumor grade progressed. Further, PD-L1 promoted HNSCC cell proliferation both in vitro and in vivo. PD-L1 depletion led to a downregulation of mTOR signaling, and mTOR inhibitor prevented the PD-L1-mediated proliferative effect. These findings increased the current understanding of PD-L1-mediated carcinogenesis in HNSCC, and may be conducive in discovering novel therapeutic targets in HNSCC.

\section{Acknowledgements}

Not applicable.

\section{Funding}

The present study was supported by the National Natural Science Foundation of China (grant nos. 81372880 and 81670910) and the Guidance Fund of the Renmin Hospital of Wuhan University (grant no. RMYD2018Z12).

\section{Availability of data and materials}

The datasets used during the present study are available from the corresponding author upon reasonable request.

\section{Authors' contributions}

$\mathrm{ZT}$ and $\mathrm{AZ}$ conceived and designed the experiments. AZ, FL, FC, JZ, LW, YW, SC and BX performed the experiments. AZ and $Z T$ analyzed the data and wrote the paper. $Z T$ and FL revised the paper. All authors read and approved the final manuscript.

\section{Ethics approval and consent to participate}

All experimental protocols were approved by the Wuhan University (Wuhan, China).

\section{Patient consent for publication}

Not applicable.

\section{Competing interests}

The authors declare that they have no competing interests.

\section{References}

1. Giraldi L, Leoncini E, Pastorino R, Wünsch-Filho V, de Carvalho M, Lopez R, Cadoni G, Arzani D, Petrelli L, Matsuo K, et al: Alcohol and cigarette consumption predict mortality in patients with head and neck cancer: A pooled analysis within the International Head and Neck Cancer Epidemiology (INHANCE) Consortium. Ann Oncol 28: 2843-2851, 2017.

2. Kawakita D, Lee YA, Turati F, Parpinel M, Decarli A, Serraino D, Matsuo K, Olshan AF, Zevallos JP, Winn DM, et al: Dietary fiber intake and head and neck cancer risk: A pooled analysis in the International Head and Neck Cancer Epidemiology consortium. Int J Cancer 141: 1811-1821, 2017.

3. Pulte D and Brenner H: Changes in survival in head and neck cancers in the late 20th and early 21st century: A period analysis. Oncologist 15: 994-1001, 2010

4. Cohen EEW, Licitra LF, Burtness B, Fayette J, Gauler T, Clement PM, Grau JJ, Del Campo JM, Mailliez A, Haddad RI, et al: Biomarkers predict enhanced clinical outcomes with afatinib versus methotrexate in patients with second-line recurrent and/or metastatic head and neck cancer. Ann Oncol 28: 2526-2532, 2017.

5. Dong H, Zhu G, Tamada K and Chen L: B7-H1, a third member of the B7 family, co-stimulates T-cell proliferation and interleukin-10 secretion. Nat Med 5: 1365-1369, 1999.

6. Hirano F, Kaneko K, Tamura H, Dong H, Wang S, Ichikawa M, Rietz C, Flies DB, Lau JS, Zhu G, et al: Blockade of B7-H1 and PD-1 by monoclonal antibodies potentiates cancer therapeutic immunity. Cancer Res 65: 1089-1096, 2005.

7. Xia Y, Jeffrey Medeiros L and Young KH: Signaling pathway and dysregulation of PD1 and its ligands in lymphoid malignancies. Biochim Biophys Acta 1865: 58-71, 2016.

8. Rollins MR and Gibbons JR: CD80 expressed by $\mathrm{CD}^{+} \mathrm{T}$ cells contributes to PD-L1-induced apoptosis of activated CD8 ${ }^{+}$ T cells. J Immunol Res 2017: 7659462, 2017.

9. Zandberg DP and Strome SE: The role of the PD-L1: PD-1 pathway in squamous cell carcinoma of the head and neck. Oral Oncol 50: 627-632, 2014.

10. Topalian SL, Drake CG and Pardoll DM: Immune checkpoint blockade: A common denominator approach to cancer therapy. Cancer Cell 27: 450-461, 2015.

11. Topalian SL, Drake CG and Pardoll DM: Targeting the PD-1/B7-H1(PD-L1) pathway to activate antitumor immunity. Curr Opin Immunol 24: 207-212, 2012.

12. Clark CA, Gupta HB, Sareddy G, Pandeswara S, Lao S, Yuan B, Drerup JM, Padron A, Conejo-Garcia J, Murthy K, et al: Tumor-intrinsic PD-L1 signals regulate cell growth, pathogenesis, and autophagy in ovarian cancer and melanoma. Cancer Res 76: 6964-6974, 2016.

13. Alsuliman A, Colak D, Al-Harazi O, Fitwi H, Tulbah A, Al-Tweigeri T, Al-Alwan M and Ghebeh H: Bidirectional crosstalk between PD-L1 expression and epithelial to mesenchymal transition: Significance in claudin-low breast cancer cells. Mol Cancer 14: 149, 2015.

14. Cao Y, Zhang L, Kamimura Y, Ritprajak P, Hashiguchi M, Hirose S and Azuma M: B7-H1 overexpression regulates epithelial-mesenchymal transition and accelerates carcinogenesis in skin. Cancer Res 71: 1235-1243, 2011.

15. Fang X, Chen C, Xia F, Yu Z, Zhang Y, Zhang F, Gu H, Wan J, Zhang X, Weng W, et al: CD274 promotes cell cycle entry of leukemia-initiating cells through JNK/Cyclin D2 signaling. J Hematol Oncol 9: 124, 2016. 
16. Ghebeh H, Tulbah A, Mohammed S, Elkum N, Bin Amer SM, Al-Tweigeri T and Dermime S: Expression of B7-H1 in breast cancer patients is strongly associated with high proliferative Ki-67-expressing tumor cells. Int J Cancer 121: 751-758, 2007.

17. Shi SJ, Wang LJ, Wang GD, Guo ZY, Wei M, Meng YL, Yang AG and Wen WH: B7-H1 expression is associated with poor prognosis in colorectal arcinoma and regulates the proliferation and invasion of HCT116 colorectal cancer cells. PLoS One 8: e76012, 2013.

18. Livak KJ and Schmittgen TD: Analysis of relative gene expression data using real-time quantitative PCR and the $2^{-\Delta \Delta C T}$ method. Methods 25: 402-408, 2001.

19. Chamoto K, Al-Habsi M and Honjo T: Role of PD-1 in immunity and diseases. Curr Top Microbiol Immunol 410: 75-97, 2017.

20. Nishimura $H$, Nose $M$, Hiai $H$, Minato $N$ and Honjo $T$ : Development of lupus-like autoimmune diseases by disruption of the PD-1 gene encoding an ITIM motif-carrying immunoreceptor. Immunity 11: 141-151, 1999.

21. Dong H, Strome SE, Salomao DR, Tamura H, Hirano F, Flies DB, Roche PC, Lu J, Zhu G, Tamada K, et al: Tumor-associated B7-H1 promotes T-cell apoptosis: A potential mechanism of immune evasion. Nat Med 8: 793-800, 2002.

22. Boussiotis VA: Molecular and biochemical aspects of the PD-1 checkpoint pathway. N Engl J Med 375: 1767-1778, 2016.

23. Topalian SL, Hodi FS, Brahmer JR, Gettinger SN, Smith DC, McDermott DF, Powderly JD, Carvajal RD, Sosman JA, Atkins MB, et al: Safety, activity, and immune correlates of anti-PD-1 antibody in cancer. N Engl J Med 366: 2443-2454, 2012.

24. Brahmer JR, Tykodi SS, Chow LQ, Hwu WJ, Topalian SL, Hwu P, Drake CG, Camacho LH, Kauh J, Odunsi K, et al: Safety and activity of anti-PD-L1 antibody in patients with advanced cancer. N Engl J Med 366: 2455-2465, 2012.

25. Baumeister SH, Freeman GJ, Dranoff G and Sharpe AH: Coinhibitory pathways in immunotherapy for cancer. Annu Rev Immunol 34: 539-573, 2016.

26. Ahmad SM, Borch TH, Hansen $M$ and Andersen $\mathrm{MH}$ PD-L1-specific T cells. Cancer Immunol Immunother 65 797-804, 2016.

27. Kleffel S, Posch C, Barthel SR, Mueller H, Schlapbach C, Guenova E, Elco CP, Lee N, Juneja VR, Zhan Q, et al: Melanoma cell-intrinsic PD-1 receptor functions promote tumor growth. Cell 162: 1242-1256, 2015.

28. Chen L, Gibbons DL, Goswami S, Cortez MA, Ahn YH, Byers LA, Zhang X, Yi X, Dwyer D, Lin W, et al: Metastasis is regulated via microRNA-200/ZEB1 axis control of tumour cell PD-L1 expression and intratumoral immunosuppression. Nat Commun 5: 5241, 2014

29. Mak MP, Pan T, Diao L, Cardnell RJ, Gibbons DL, William WN, Skoulidis F, Parra ER, Rodriguez-Canales J, Wistuba II, et al: A patient-derived, pan-cancer EMT signature identifies global molecular alterations and immune target enrichment following epithelial to mesenchymal transition. Clin Cancer Res 22: 609-620, 2016

30. Ritprajak P and Azuma M: Intrinsic and extrinsic control of expression of the immunoregulatory molecule PD-L1 in epithelial cells and squamous cell carcinoma. Oral Oncol 51: 221-228, 2015 .
31. Strome SE, Dong H, Tamura H, Voss SG, Flies DB, Tamada K, Salomao D, Cheville J, Hirano F, Lin W, et al: B7-H1 blockade augments adoptive T-cell immunotherapy for squamous cell carcinoma. Cancer Res 63: 6501-6505, 2003.

32. Hsu MC, Hsiao JR, Chang KC, Wu YH, Su IJ, Jin YT and Chang Y: Increase of programmed death-1-expressing intratumoral CD8 T cells predicts a poor prognosis for nasopharyngeal carcinoma. Mod Pathol 23: 1393-1403, 2010.

33. Muenst S, Schaerli AR, Gao F, Däster S, Trella E, Droeser RA, Muraro MG, Zajac P, Zanetti R, Gillanders WE, et al: Expression of programmed death ligand 1 (PD-L1) is associated with poor prognosis in human breast cancer. Breast Cancer Res Treat 146: 15-24, 2014.

34. Chang CH, Qiu J, O'Sullivan D, Buck MD, Noguchi T, Curtis JD, Chen Q, Gindin M, Gubin MM, van der Windt GJ, et al: Metabolic competition in the tumor microenvironment is a driver of cancer progression. Cell 162: 1229-1241, 2015.

35. Francisco LM, Salinas VH, Brown KE, Vanguri VK, Freeman GJ, Kuchroo VK and Sharpe AH: PD-L1 regulates the development, maintenance, and function of induced regulatory T cells. J Exp Med 206: 3015-3029, 2009.

36. Follo MY, Manzoli L, Poli A, McCubrey JA and Cocco L: PLC and PI3K/Akt/mTOR signalling in disease and cancer. Adv Biol Regul 57: 10-16, 2015.

37. Jhanwar-Uniyal M, Amin AG, Cooper JB, Das K, Schmidt MH and Murali R: Discrete signaling mechanisms of mTORC1 and mTORC2: Connected yet apart in cellular and molecular aspects. Adv Biol Regul 64: 39-48, 2017.

38. Hermida MA, Dinesh Kumar J and Leslie NR: GSK3 and its interactions with the PI3K/AKT/mTOR signalling network. Adv Biol Regul 65: 5-15, 2017.

39. Bertacchini J, Frasson C, Chiarini F, D'Avella D, Accordi B, Anselmi L, Barozzi P, Forghieri F, Luppi M, Martelli AM, et al: Dual inhibition of PI3K/mTOR signaling in chemoresistant AML primary cells. Adv Biol Regul 68: 2-9, 2018.

40. Thedieck K, Holzwarth B, Prentzell MT, Boehlke C, Kläsener K, Ruf S, Sonntag AG, Maerz L, Grellscheid SN, Kremmer E, et al: Inhibition of mTORC1 by astrin and stress granules prevents apoptosis in cancer cells. Cell 154: 859-874, 2013.

41. Liu P, Gan W, Inuzuka H, Lazorchak AS, Gao D, Arojo O, Liu D, Wan L, Zhai B, Yu Y, et al: Sin1 phosphorylation impairs mTORC2 complex integrity and inhibits downstream Akt signalling to suppress tumorigenesis. Nat Cell Biol 15: 1340-1350, 2013.

42. Herbst RS, Soria JC, Kowanetz M, Fine GD, Hamid O, Gordon MS, Sosman JA, McDermott DF, Powderly JD, Gettinger SN, et al: Predictive correlates of response to the anti-PD-L1 antibody MPDL3280A in cancer patients. Nature 515: 563-567, 2014.

43. Stewart R, Morrow M, Hammond SA, Mulgrew K, Marcus D, Poon E, Watkins A, Mullins S, Chodorge M, Andrews J, et al: Identification and characterization of MEDI4736, an antagonistic anti-PD-L1 monoclonal antibody. Cancer Immunol Res 3: 1052-1062, 2015.

This work is licensed under a Creative Commons Attribution-NonCommercial-NoDerivatives 4.0 International (CC BY-NC-ND 4.0) License. 